\title{
Author Correction: DART takes aim at community editing
}

Connie W. Y. Ha and Suzanne Devkota (1)

Correction to: Nature Microbiology https://doi.org/10.1038/s41564-021-01017-4, published online 6 December 2021.

In the version of this article initially published online, there was an error in the first sentence of the second paragraph. In the text now reading "...toolkit that agnostically pre-screens for the most genomically accepting bacteria within a mixed community and utilizes barcoded CRISPR-Cas Tn7 transposases," CRISPR-Cas replaces "CRISPR-Cas9." The change has been made to the online version of the article.

Published online: 6 January 2022

https://doi.org/10.1038/s41564-022-01057-4

๑) Springer Nature Limited 2022 